\title{
TEKNOLOGI LOCATION BASED SERVICE (GLOBAL POSITIONING SYSTEM) PADA PERANGKAT MOBILE
}

\author{
Budi Yulianto \\ Jurusan Teknik Informatika, Fakultas Ilmu Komputer, Universitas Bina Nusantara \\ Jln. K.H. Syahdan No. 9, Palmerah, Jakarta Barat 11480 \\ laboratory@binus.ac.id
}

\begin{abstract}
Article presents analysis and design of software using Location Based Service (LBS) that is part of communication technology based on geographic position. The goal of the research is designing LBS application to be implemented on mobile device that has GPS (Global Positioning System) technology and uses GPRS (General Packet Radio Service) to connect to server for generating shortest path by Dijkstra algorithm method Fibonacci Heap. Software development method used is LBS application implemented on mobile device. Conclusion of the research has shown that shortest path generated using Dijkstra algorithm method Fibonacci Heap as single source shortest path is faster than Dijkstra algorithm and Bellman Ford.
\end{abstract}

Keywords: location based service, mobile device, global positioning system

\begin{abstract}
ABSTRAK
Artikel menjelaskan analisis dan perancangan perangkat lunak menggunakan teknologi Location Based Service (LBS) yang merupakan bagian dari teknologi komunikasi berbasiskan pada posisi lokasi geografi. Tujuan penelitian adalah merancang aplikasi LBS untuk diimplementasikan pada perangkat mobile berteknologi GPS (Global Positioning System) serta menggunakan GPRS (General Packet Radio Service) sebagai penghubung dengan server untuk menghasilkan rute terpendek dengan menggunakan algoritma Dijkstra metode Fibonacci Heap. Metode pengembangan piranti lunak yang digunakan adalah Rational Unified Process. Hasil penelitian merupakan perancangan aplikasi LBS yang dapat diimplementasikan pada perangkat mobile. Simpulan dari penelitian menunjukkan pencarian rute terpendek dengan algoritma Dijkstra metode Fibonacci Heap sebagai algoritma single source shortest path yang lebih cepat daripada algoritma Dijkstra biasa dan Bellman Ford.
\end{abstract}

Kata kunci: location based service, perangkat mobile, global positioning system 


\section{PENDAHULUAN}

Perkembangan teknologi sekarang ini telah membawa manusia pada tahap di mana kebutuhan hidup telah berubah ke arah digital sehingga lebih mudah, menarik, dan beragam. Salah satu kebutuhan manusia yang dari hari ke hari menjadi semakin vital adalah kebutuhan komunikasi sebagai suatu aliran informasi. Layanan yang memanfaatkan kemajuan teknologi komunikasi atau Location Based Service (LBS) berguna untuk menemukan posisi geografi atau posisi seseorang dari peralatan bergerak (perangkat mobile) pada suatu waktu. Informasi berupa posisi ini dapat berkembang menjadi layanan pencarian rute terpendek dari suatu posisi ke posisi lain menggunakan suatu algoritma shortest path.

Perpaduan antara posisi dan rute terpendek ini akan menjadi suatu aplikasi yang berguna dalam memenuhi kebutuhan akan informasi lokasi (tempat) bagi masyarakat, khususnya bagi mereka yang banyak melakukan pekerjaan atau aktivitas dan menghabiskan waktu di luar bangunan. Perangkat pencarian tersebut menyediakan data dalam bentuk visual (grafik) yang dapat diakses secara cepat dan murah. Selain tempat wisata, informasi lokasi tersebut dapat pula berupa hotel, restoran, dan tempat berbelanja.

Perangkat pencarian tersebut memerlukan Global Positioning System (GPS) yang pada dasarnya dikembangkan untuk memberikan informasi posisi geografi. GPS telah digunakan secara luas pada berbagai wilayah dan aktivitas oleh pengguna seperti pengendara kendaraan, penjelajah alam, pelayar, dan pengguna lainnya yang membutuhkan informasi posisi geografi sebagai panduan. Aplikasi GPS pada umumnya terintegrasi pada kendaraan dan beberapa dirancang pada Personal Digital Assistant (PDA).

Tujuan penelitian adalah menganalisis, merancang dan menghasilkan sebuah aplikasi LBS yang dapat menampilkan rute terpendek dari suatu lokasi ke lokasi lainnya dengan menggunakan algoritma Dijkstra; Menyediakan peta lokasi wisata dan tempat umum yang berskala kecil ke pengguna. Manfaat penelitian adalah agar pengguna dapat mengetahui lokasi tempat dia berada; Membantu pengguna mencari lokasi umum yang dibutuhkan; Memberikan jalur terpendek dari lokasi pengguna yang terlacak dengan lokasi umum yang dituju.

\section{METODE PENELITIAN}

Metode penelitian yang digunakan meliputi studi pustaka dan studi lapangan. Pada metode studi pustaka, dilakukan pengumpulan bahan-bahan pustaka baik yang dilakukan di perpustakaan maupun pencarian melalui internet. Metode ini berguna dalam membantu memperdalam pembahasan materi, pembuatan program aplikasi, dan penyusunan laporan penelitian. Pada metode studi lapangan, dilakukan penambahan data dari pengguna perangkat mobile melalui kuesioner. Metode ini berguna untuk mengetahui kebutuhan pengguna, model tampilan yang disukai, dan kemudahan pengoperasian.

\section{Metode Pengembangan}

Metode pengembangan perangkat lunak yang digunakan adalah Rational Unified Process (RUP) yang meliputi empat tahap, yaitu Tahap Permulaan (Inception Phase) mencakup arsitektural proyek meliputi Model, View, Controller (MVC) design pattern, dan pencarian data meliputi studi pustaka dan studi lapangan; Tahap Perluasan (Elaboration Phase) mencakup penentuan perangkat keras, database, perangkat mobile, dan algoritma pencarian rute terpendek; Tahap Pembuatan (Construction Phase) mencakup perancangan dan dokumentasi piranti lunak; Tahap Peralihan (Transition Phase) mencakup implementasi dan pengujian piranti lunak. 


\section{Studi Pustaka}

Sistem koordinat adalah suatu sistem yang menentukan sekumpulan bilangan ke masingmasing titik pada suatu ruang berdimensi $n$. Sistem koordinat ini merupakan aturan yang dapat membantu dalam pengukuran jarak antara titik-titik yang ada.

Shortest path adalah jalur terpendek yang dihasilkan melalui pencarian rute atau path terpendek antara node sumber dengan node tujuan yang ada pada graph. Biaya (cost) yang dihasilkan adalah yang paling minimum berdasarkan perhitungan pada edge-nya. Pada penelitian ini, nilai pada masing-masing edge merupakan panjang jalan yang harus ditempuh. Pencarian shortest path bukan berarti langsung menemukan jarak dari node awal ke node tujuan tetapi ada kalanya usaha itu harus dilakukan dengan melewati node-node tertentu sehingga tujuan akhir node dapat tercapai.

Single source shortest path adalah jarak terpendek (shortest path) dari setiap verteks tunggal pada graph berarah yang berbobot menuju verteks tujuan tertentu. Disebut single source karena membutuhkan dua titik sebagai awal pencarian. Yang termasuk dalam algoritma single source shortest path ini adalah Algoritma Dijkstra dan Bellman Ford.

Algoritma Dijkstra dibuat oleh Edsgar Wybe Dijkstra untuk menemukan path bernilai terkecil (rute terpendek) dari verteks awal tunggal ke semua verteks pada graph. Algoritma ini akan melihat verteks yang terdeteksi dengan verteks awal, melihat successor dari verteks tersebut kemudian memperbarui jaraknya dari awal, demikian seluruhnya sampai verteks tujuan berhasil ditemukan. Hasilnya pasti berupa path terpendek.

Fibonacci-Heap berasal dari bilangan Fibonacci yang digunakan untuk analisis waktu proses. Fibonacci-Heap diterapkan dalam menghasilkan waktu proses yang terbaik pada beberapa algoritma graph, termasuk algoritma Dijkstra dan Prim. Fibonacci-Heap dapat digunakan untuk meningkatkan waktu proses pada algoritma Dijkstra dalam menghitung jarak terpendek pada suatu graph dan pada algoritma Prim untuk mendapatkan minimum spanning tree pada suatu graph.

Rational Unified Process adalah metode pengembangan piranti lunak hasil dari proses pengembangan model spiral. Rational Unified Process memiliki karakteristik seperti halnya produk piranti lunak, dirancang dan didokumentasikan menggunakan Unified Modeling Language (UML). Bentuk prosesnya memiliki dua struktur atau dimensi meliputi Dimensi Horizontal yang merepresentasikan waktu dan menampilkan aspek daur hidup dari proses; Dimensi Vertikal yang merepresentasikan proses inti (atau aliran kerja) untuk menggabungkan aktivitas rekayasa piranti lunak berdasarkan sifatnya.

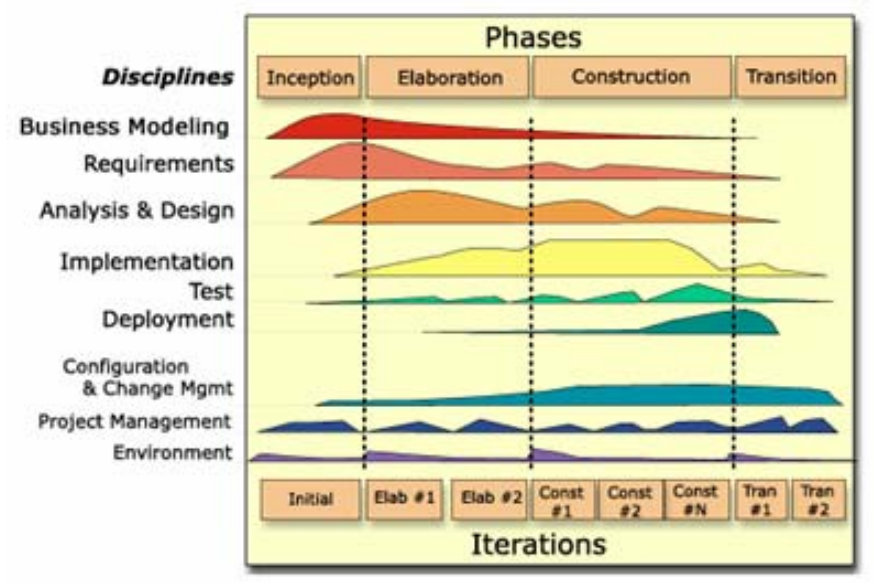

Gambar 1 Dua Dimensi pada RUP

(http://en.wikipedia.org/wiki/Image:RationalUnifiedProcess.png) 


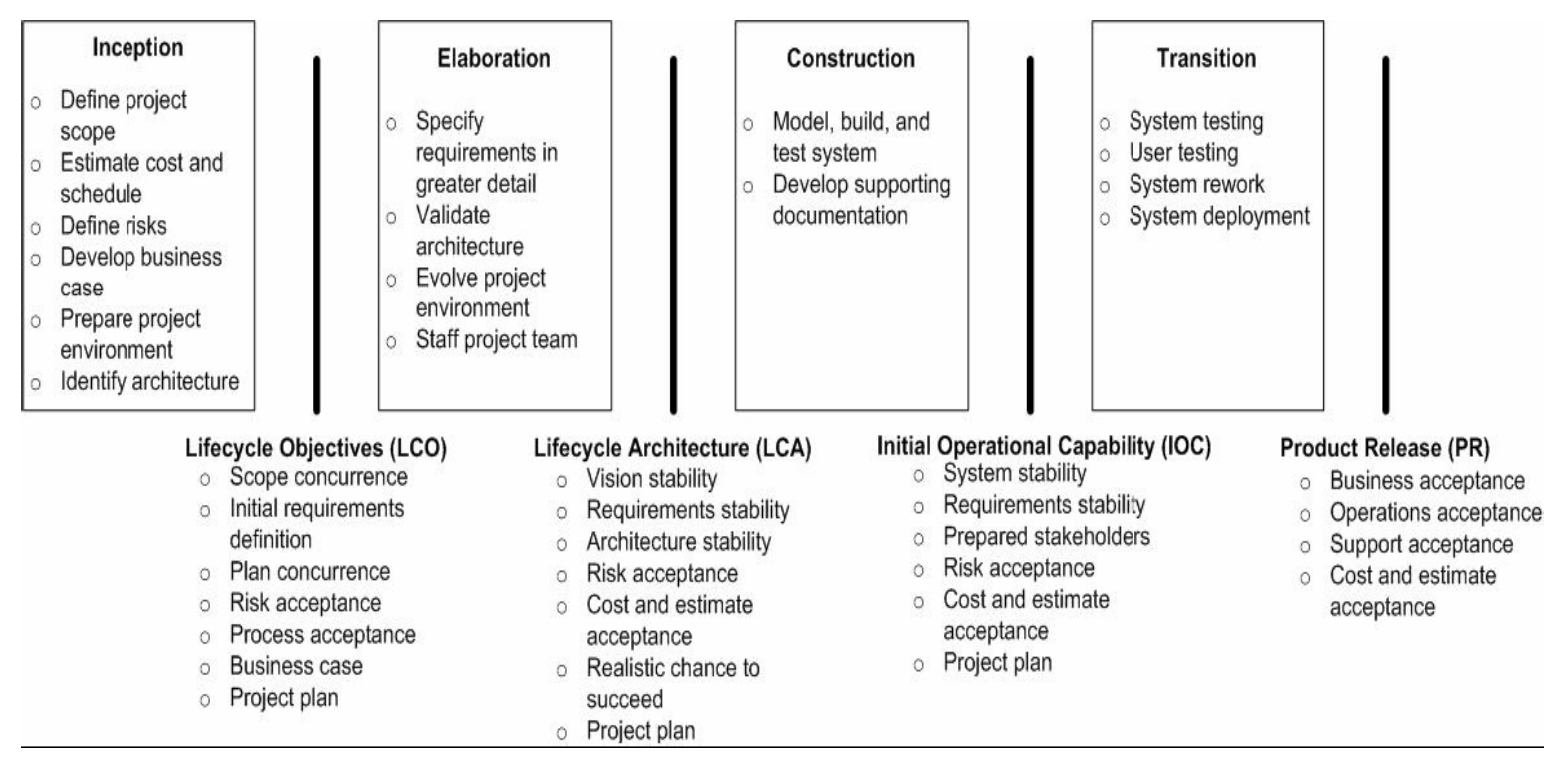

Gambar 2 Tahapan pada RUP

(http://www.ambysoft.com/downloads/managersIntroToRUP.pdf)

Location Based Service (LBS) adalah suatu layanan yang berbasiskan pada posisi lokasi geografinya yang disediakan kepada pelanggan. Dengan demikian teknologi LBS memungkinkan pengguna untuk mencari tempat-tempat yang diinginkan seperti hotel terdekat, ATM terdekat, SPBU terdekat, alamat tertentu dan sebagainya. Pada dasarnya pencarian lokasi dengan LBS sama dengan pencarian lokasi menggunakan peta biasa, hanya saja LBS dapat memberikan informasi tambahan mengenai posisi benda bergerak.

Magon dan Shukla, pada artikelnya yang berjudul "LBS, the Ingredients and the Alternatives", menyatakan komponen-komponen yang dibutuhkan untuk LBS meliputi lima hal, yaitu Lokasi atau Posisi yang mencakup latitude (posisi utara atau selatan), longitude (posisi timur atau barat), dan altitude (ketinggian dari permukaan laut); Data Geografi menyediakan data komponen lokasi seperti jaringan jalan, alamat pengguna, bangunan, dan daerah seperti pegunungan dan sungai, termasuk juga lokasi gas, restoran, hotel, dan sebagainya; Pusat Kendali yang bertindak sebagai pusat pengelolaan data dan distribusi layanan lokasi; Data Lokasi atau Data Peta dikelola dan dimanipulasi untuk menyediakan beberapa layanan yang berdasarkan pada lokasi pengguna; Sistem Komunikasi untuk menyampaikan lokasi ke pusat kendali dan menyediakan layanan yang diperlukan.

Global Positioning System (GPS) adalah suatu sistem navigasi satelit yang berfungsi untuk menentukan lokasi, kecepatan, dan arah, melalui signal yang diterima lebih dari 24-32 satelit yang berorbit $20000 \mathrm{~km}$ (11000 mil laut) di atas bumi. Prinsip dasar di balik GPS adalah pengukuran jarak (distance/range) antara satelit dan receiver dari transmisi signal radio. Sebuah GPS receiver memerlukan empat atau lebih satelit untuk menghasilkan jarak mereka, dan menggunakan informasi ini untuk menyimpulkan lokasi mereka. Operasi ini disebut triangulation.

Satelit-satelit GPS mentransmisikan signal radio ke bumi yang mengandung informasi tentang satelit, contohnya lokasi dan waktu saat itu, menginformasikan pengguna secara tepat di mana satelit berada dalam orbit mereka sementara GPS receivers secara pasif menerima signal satelit tersebut. Semua satelit-satelit GPS menyinkronisasi operasi-operasi agar signal-signal yang berulang ini ditransmisikan pada waktu yang bersamaan. 


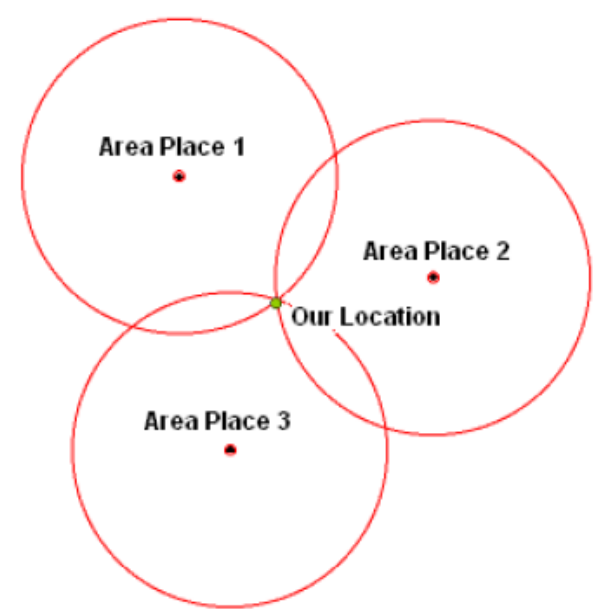

Gambar 3 Area Pertama, Kedua dan Ketiga (http://www.sfu.ca/gis/bguide/icons/Fig3_1_GPS.gif)

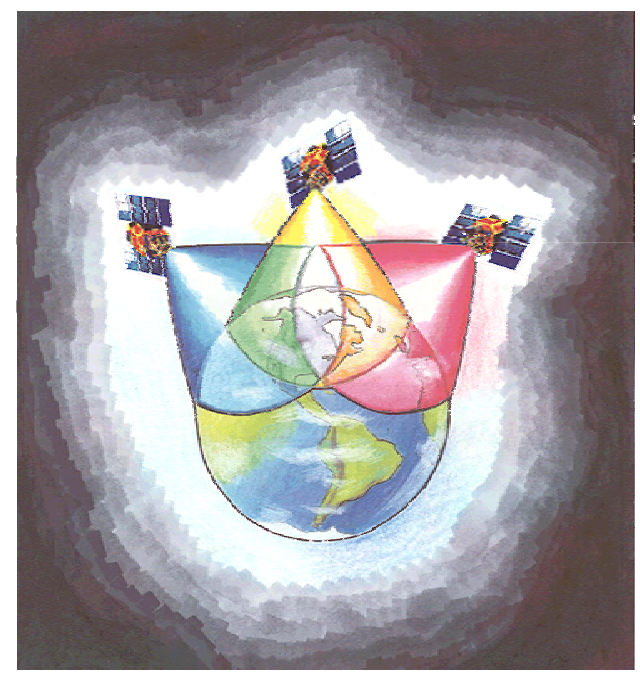

Gambar 4 Triangulation

(http://ww2.it.nuigalway.ie/staff/h_melvin/threesat.gif)

Rumus yang digunakan untuk menghitung jarak adalah rumus Great Circle Distance, yaitu Great Circle Distance = RadiusBumi * ACOS ( COS(RADIAN(90-(Lat1*24))) * COS(RADIAN(90$($ Lat2*24)) $)+\operatorname{SIN}($ RADIAN(90-(Lat1*24))) * SIN(RADIAN(90-(Lat2*24))) * COS(RADIAN(24*(Long1-Long2))) )

Lat1 adalah latitude nilai 1, dalam DD:MM:SS;

Long1 adalah longitude nilai 1, dalam DD:MM:SS;

Lat2 adalah latitude nilai 2, dalam DD:MM:SS;

Long2 adalah longitude nilai 2, dalam DD:MM:SS;

RadiusBumi adalah radius bumi (3963 mil atau 6377 kilometer).

NMEA (atau NMEA 0183) adalah spesifikasi data untuk komunikasi antara mesin marine (laut) dan lainnya dengan GPS receivers dalam menghasilkan informasi posisi saat itu. Komunikasi GPS receiver menggunakan spesifikasi NMEA pada transmisi data mereka. Data ini termasuk solusi lengkap PVT (position, velocity, time) yang dihitung oleh GPS receiver. Gagasan NMEA adalah 
mengirimkan sebarisan data yang disebut kalimat yang secara keseluruhan termasuk dirinya dan bebas dari kalimat lainnya. Jenis kalimat yang paling sering digunakan adalah RMA, RMB, RMC, GGA, GSA, dan VTG.

General Packet Radio Service (GPRS) adalah suatu layanan transimisi data pada perangkat mobile yang disediakan pada pengguna. Biaya penggunaan untuk transmisi data menggunakan GPRS dihitung per megabyte, sementara yang lain pada umumnya dihitung per menit waktu koneksi. GPRS dapat digunakan untuk layanan seperti WAP, SMS, MMS, layanan komunikasi internet. Di masa berikutnya, GPRS diharapkan dapat mengurangi biaya komunikasi antar telepon melalui VoIP (Voice over IP).

\section{HASIL DAN PEMBAHASAN}

\section{Analisis Algoritma}

Data-data yang akurat diperlukan dalam penelitian agar dapat menghasilkan informasi yang berguna. Data-data tersebut adalah data posisi pengguna, data nama tempat, dan data jalan. Dalam representasi graph untuk pencarian rute terpendek, jalan diibaratkan sebagai edge dan diberi simpul (node) sebagai batas jalan.

Analisis algoritma dilakukan untuk mengetahui efektifitas dari beberapa algoritma single source shortest path, algoritma Bellman Ford dan Dijkstra sehingga dapat diketahui algoritma yang lebih baik untuk pencarian rute terpendek pada aplikasi yang akan dibuat. Adapun analisis yang akan dilakukan adalah time complexity, yaitu jumlah langkah yang dilakukan pada suatu program untuk mengeksekusi fungsi yang ditulis.

Tabel 1 Time Complexity pada Algoritma Bellman Ford

\begin{tabular}{|c|c|c|c|c|c|c|c|c|c|c|c|c|c|}
\hline \multirow[t]{2}{*}{ No } & \multirow[t]{2}{*}{$\begin{array}{l}\text { Node } \\
\text { Awal }\end{array}$} & \multirow[t]{2}{*}{$\begin{array}{l}\text { Node } \\
\text { Akhir }\end{array}$} & \multicolumn{11}{|c|}{$\begin{array}{c}\text { Bellman Ford } \\
\text { Waktu (micro-second) }\end{array}$} \\
\hline & & & \begin{tabular}{|l|} 
Test 1 \\
\end{tabular} & \begin{tabular}{|l|} 
Test 2 \\
\end{tabular} & \begin{tabular}{|l|} 
Test 3 \\
\end{tabular} & \begin{tabular}{|l|} 
Test 4 \\
\end{tabular} & \begin{tabular}{|l|} 
Test 5 \\
\end{tabular} & \begin{tabular}{|l|} 
Test 6 \\
\end{tabular} & \begin{tabular}{|l|} 
Test 7 \\
\end{tabular} & Test 8 & \begin{tabular}{|l|} 
Test 9 \\
\end{tabular} & \begin{tabular}{|l|} 
Test 10 \\
\end{tabular} & Rata-rata \\
\hline 1 & 1 & 500 & 12073.08 & 11532.49 & 12196.31 & 11649.83 & 12696.14 & 12220.40 & 10489.24 & 12392.03 & 13511.18 & 10260.99 & \\
\hline 2 & 10 & 485 & 12085.80 & 11636.34 & 11910.09 & & 11377.16 & & 11596.58 & & & & \\
\hline 3 & 17 & 60 & 11845.81 & 12022.06 & 11853.92 & 11858.06 & 11631.32 & & \begin{tabular}{|c|}
11001.78 \\
\end{tabular} & 11962.99 & & & \\
\hline 4 & 21 & 277 & 122 & 11934.40 & 11809.33 & .05 & 31.49 & & 44 & 12271.49 & 11784 & 5.52 & \\
\hline 5 & 66 & 490 & 59 & & & & 8.92 & & 13.32 & & & & \\
\hline 6 & 128 & 394 & 11283.03 & 11592.02 & 11654.58 & 11497.44 & 11972.88 & 11398.35 & 11565.35 & 11915.97 & 11542.91 & 11470.34 & 11589.29 \\
\hline 7 & 370 & 72 & 11742.49 & 11601.79 & 11579.49 & 11711.57 & 11767.41 & 11582.05 & 11872.26 & 11684.49 & 11566.33 & 11792.69 & 11690.06 \\
\hline 8 & 396 & 36 & 11233.48 & 11906.77 & 12046.00 & 11503.27 & 11694.22 & 11526.25 & 11971.15 & 11938.93 & 11507.11 & 11462.89 & 11679.01 \\
\hline 9 & 456 & 20 & 11644.37 & 11328.04 & 11835.98 & 11927.35 & 11873.53 & 11972.22 & 11652.02 & 11536.67 & 11393.92 & 11315.12 & 11647.92 \\
\hline 10 & 482 & 14 & 11870.07 & 11600.73 & 11925.44 & 11630.33 & 11664.77 & 12205.12 & 11886.69 & 12286.03 & 12091.56 & 12023.33 & 11918.41 \\
\hline
\end{tabular}

Tabel 2 Time Complexity pada Algoritma Dijkstra

\begin{tabular}{|c|c|c|c|c|c|c|c|c|c|c|c|c|c|}
\hline \multirow[t]{2}{*}{ No } & \multirow[t]{2}{*}{\begin{tabular}{|l|} 
Node \\
Awal
\end{tabular}} & \multirow[t]{2}{*}{$\begin{array}{l}\text { Node } \\
\text { Akhir }\end{array}$} & \multicolumn{11}{|c|}{$\begin{array}{c}\text { Dijkstra } \\
\text { Waktu (micro-second) }\end{array}$} \\
\hline & & & Test 1 & Test 2 & Test 3 & Test 4 & Test 5 & Test 6 & Test 7 & Test 8 & Test 9 & Test 10 & Rata-rata \\
\hline 1 & 1 & 500 & 23.814100 & 22.943100 & 24.067800 & 22.861500 & 24.849500 & 24.006100 & 20.824800 & 24.228400 & 26.842700 & 20.607200 & 23.50 \\
\hline 2 & 10 & 485 & 24.189000 & 23.418800 & 23.645100 & 23.966400 & 23.519400 & 23.474 & 23.905800 & 23.708800 & 24.307800 & 23.398700 & 23.753390 \\
\hline 3 & 17 & 60 & 23.7 & 23.8 & 23.7219 & 23.714400 & 23.6912 & & & & & & 050 \\
\hline 4 & 21 & 277 & 23.99 & 23.7 & & & & & & & & & \\
\hline 5 & 66 & 90 & 21.1 & & & & & & & & & & \\
\hline 6 & 128 & 394 & 22.7 & & & & & & & & & & \\
\hline 7 & & 72 & 23.284100 & 23.338200 & 23.43 & 23.36 & 23.235200 & 23.1 & 23.75 & 23.096000 & 400 & 23.602400 & 090 \\
\hline 8 & 396 & 36 & 22.885600 & 23.271800 & 23.399200 & 22.715200 & 23.296100 & 23.183600 & 23.781700 & 23.459100 & 23.044700 & 23.253700 & 23.229070 \\
\hline 9 & 456 & 20 & 22.984800 & 23.107200 & 23.703600 & 23.575100 & 23.369200 & 23.644100 & 22.880500 & 23.474900 & 23.088800 & 23.413500 & 23.324170 \\
\hline 10 & 482 & 14 & 23.729400 & 23.742200 & 23.655000 & 23.078200 & 23.652400 & 23.989200 & 23.635700 & 23.632600 & 23.776200 & 23.778300 & 23.666920 \\
\hline
\end{tabular}


Tabel 3 Time Complexity pada Algoritma Dijkstra Metode Fibonacci Heap

\begin{tabular}{|c|c|c|c|c|c|c|c|c|c|c|c|c|c|}
\hline \multirow[t]{2}{*}{ No } & \multirow[t]{2}{*}{$\begin{array}{l}\text { Node } \\
\text { Awal }\end{array} \mid$} & \multirow[t]{2}{*}{$\begin{array}{l}\text { Node } \\
\text { Akhir }\end{array} \mid$} & \multicolumn{11}{|c|}{$\begin{array}{c}\text { Dijkstra dengan metode Fibonacci-Heap } \\
\text { Waktu (micro-second) }\end{array}$} \\
\hline & & & Test 1 & Test 2 & Test 3 & Test 4 & \begin{tabular}{|l|} 
Test 5 \\
\end{tabular} & Test 6 & Test 7 & Test 8 & Test 9 & Test 10 & Rata-rata \\
\hline 1 & 1 & 500 & 2.273232 & 2.273232 & 2.295914 & 2.270268 & 2.325160 & 2.290566 & 1.672970 & 2.302104 & 2.362976 & 1.669147 & 2.173557 \\
\hline 2 & 10 & 485 & 1.916032 & 1.972583 & 1.902516 & 2.084577 & 2.018182 & & 2.035057 & 1.806458 & 2.013443 & 1.949371 & 1.960675 \\
\hline 3 & 17 & & 1.87 & 2.088599 & $\mid 1.880876$ & 1.906090 & & & & & & & \\
\hline 4 & 21 & & 2.429607 & 2.32 & 2.432343 & 2.441347 & & & & & & & \\
\hline 5 & 66 & 490 & 1.765507 & 1.804355 & 1.663220 & 1.795017 & 1. & 1.5 & 4771 & 8853 & 7157 & 1.746500 & 1106 \\
\hline 6 & 128 & 394 & 2.451384 & 2.355468 & 2.556714 & 2.386625 & 2.452834 & 2.359853 & 2.465634 & 2.530954 & 2.463489 & 2.435351 & 45831 \\
\hline 7 & 370 & 72 & 2.533474 & 2.393412 & 2.549747 & 2.497319 & 2.532659 & 2.401432 & 2.429682 & 2.569652 & 2.575474 & 2.594230 & 2.507708 \\
\hline 8 & 396 & 36 & 2.637984 & 2.529495 & 2.700256 & 2.660760 & 2.668067 & 2.540852 & 2.610436 & 2.720478 & 2.658370 & 2.634041 & 2.636074 \\
\hline 9 & 456 & 20 & 2.682159 & 2.565818 & 2.646644 & 2.650289 & 2.598350 & 2.659010 & & 2.678725 & 2.661142 & 2.678581 & 2.653820 \\
\hline 10 & 482 & 14 & 2.666178 & 2.585220 & 2.686924 & 2.689975 & 2.594812 & 2.680862 & 2.680553 & 2.698504 & 2.692031 & 2.676921 & 2.665198 \\
\hline
\end{tabular}

Kesimpulan:

Pencarian rute terpendek menggunakan algoritma Dijkstra dengan metode Fibonacci Heap ternyata menghasilkan nilai waktu yang lebih kecil jika dibandingkan dengan algoritma Dijkstra biasa dan Bellman Ford. Ini berarti algoritma Dijkstra dengan metode Fibonacci Heap lebih cepat dibandingkan dengan kedua algoritma tersebut.

\section{Perancangan Sistem}

Perancangan sistem merupakan pengembangan sistem dan prosedur baru agar diketahui konsep dari sistem itu bekerja sehingga kebutuhan dan informasi yang dibutuhkan akan terdefinisi secara jelas. Sistem terbagi menjadi 3 bagian besar, yaitu Mobile Device (PDA) sebagai alat untuk meminta request rute terpendek dan menerima output dari request tersebut; Server dan Back End dimana server bertugas menerima dan mengolah informasi yang diminta oleh pengguna berdasarkan data-data yang ada di dalam database, hasil pengolahan kemudian akan dikirimkan balik oleh server ke mobile device, sedangkan back end berfungsi untuk memasukkan data dan meng-update data pada database; Database berisi semua data-data yang diperlukan pada sistem, data-data dari database akan langsung disimpan di dalam memori.

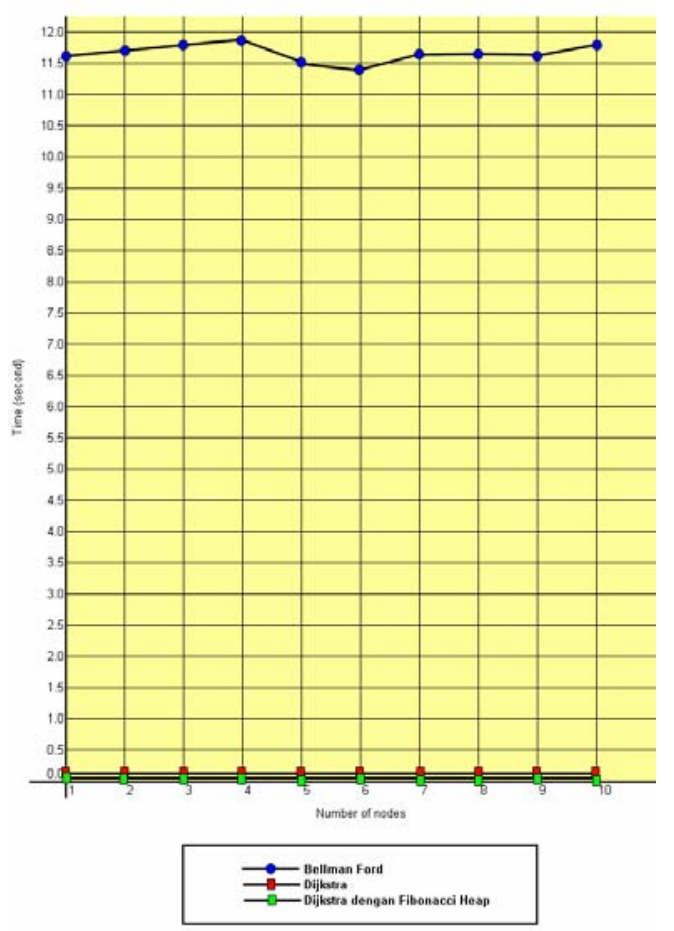

Gambar 5 Grafik Perbandingan Perhitungan Waktu dari Ketiga Algoritma 


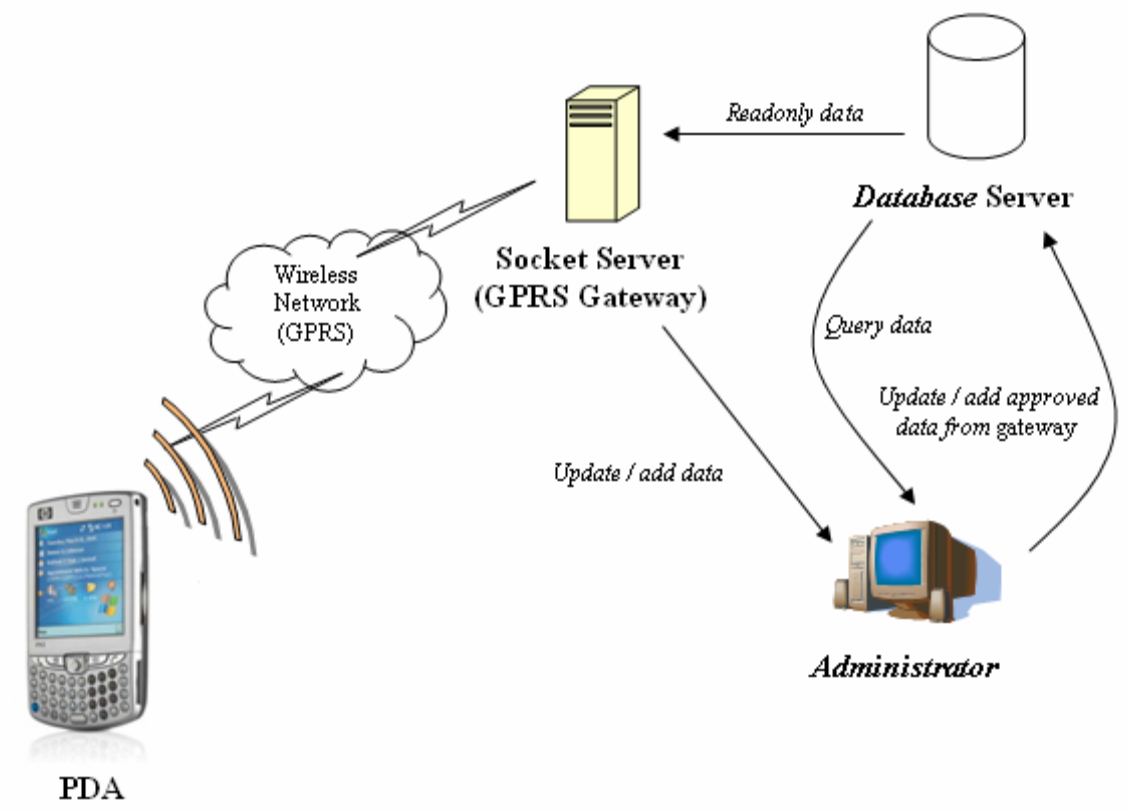

Gambar 6 Rancangan Sistem

\section{Perancangan UML}

Perancangan UML meliputi Use Case Diagram, dan Class Diagram. Use Case Diagram memberikan gambaran mengenai sistem dari sudut pandang pengguna, dimana pengguna dapat memilih kategori pilihan tempat yang hendak dituju sebagai tempat terdekat dari posisi pengguna berada. Pengguna tidak perlu memasukkan posisi dimana dia berada karena koordinat posisi pengguna akan langsung dikirimkan pada saat pengguna memilih tempat yang akan dituju. Agar informasi yang diberikan selalu merupakan informasi yang terbaru, maka informasi mengenai kondisi jalan atau kondisi lalu lintas selalu di-update oleh Administrator sedangkan data statik seperti tempat, jalan, dan karakteristik jalan akan disimpan di dalam database.

Pengguna menggunakan PDA-nya untuk memilih kategori tempat tujuan, dimana satu atau lebih pengguna hanya dapat memilih satu kategori. Lalu kategori yang dipilih tersebut digunakan untuk mencari data di tabel Vertices, data-data di tabel Vertices sendiri terhubung dengan tabel Edges, dimana satu titik di tabel Vertices menghubungkan satu atau lebih Edges. 


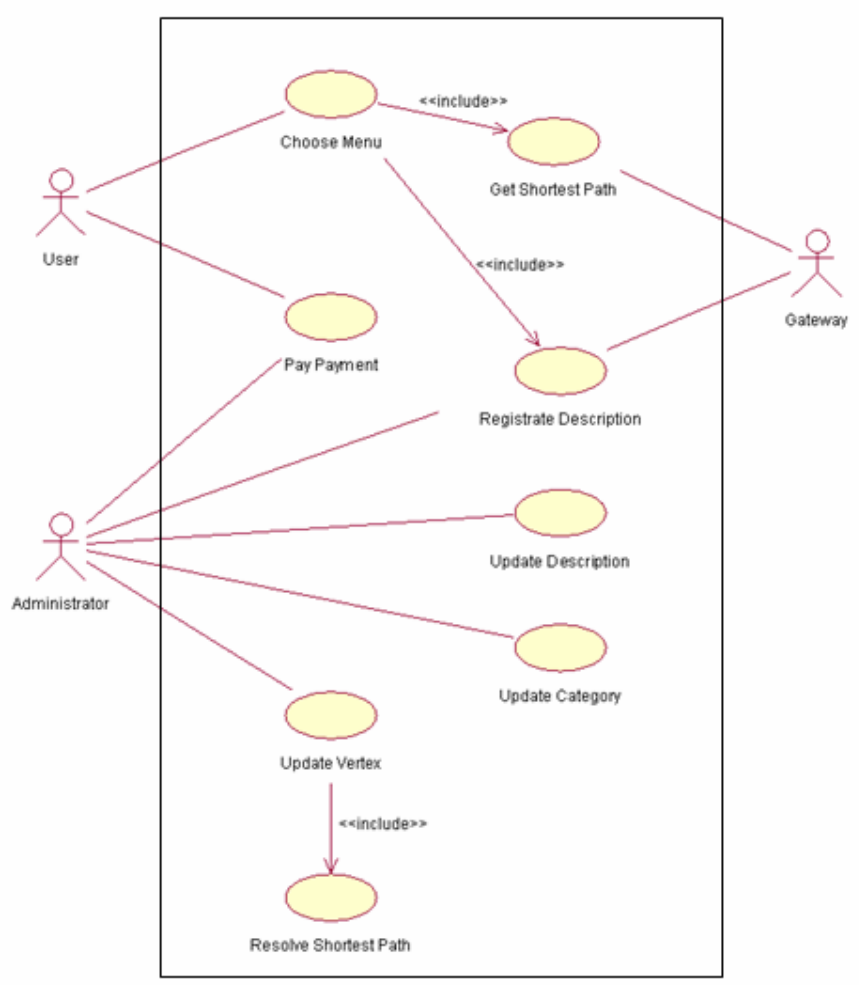

Gambar 7 Use Case Diagram

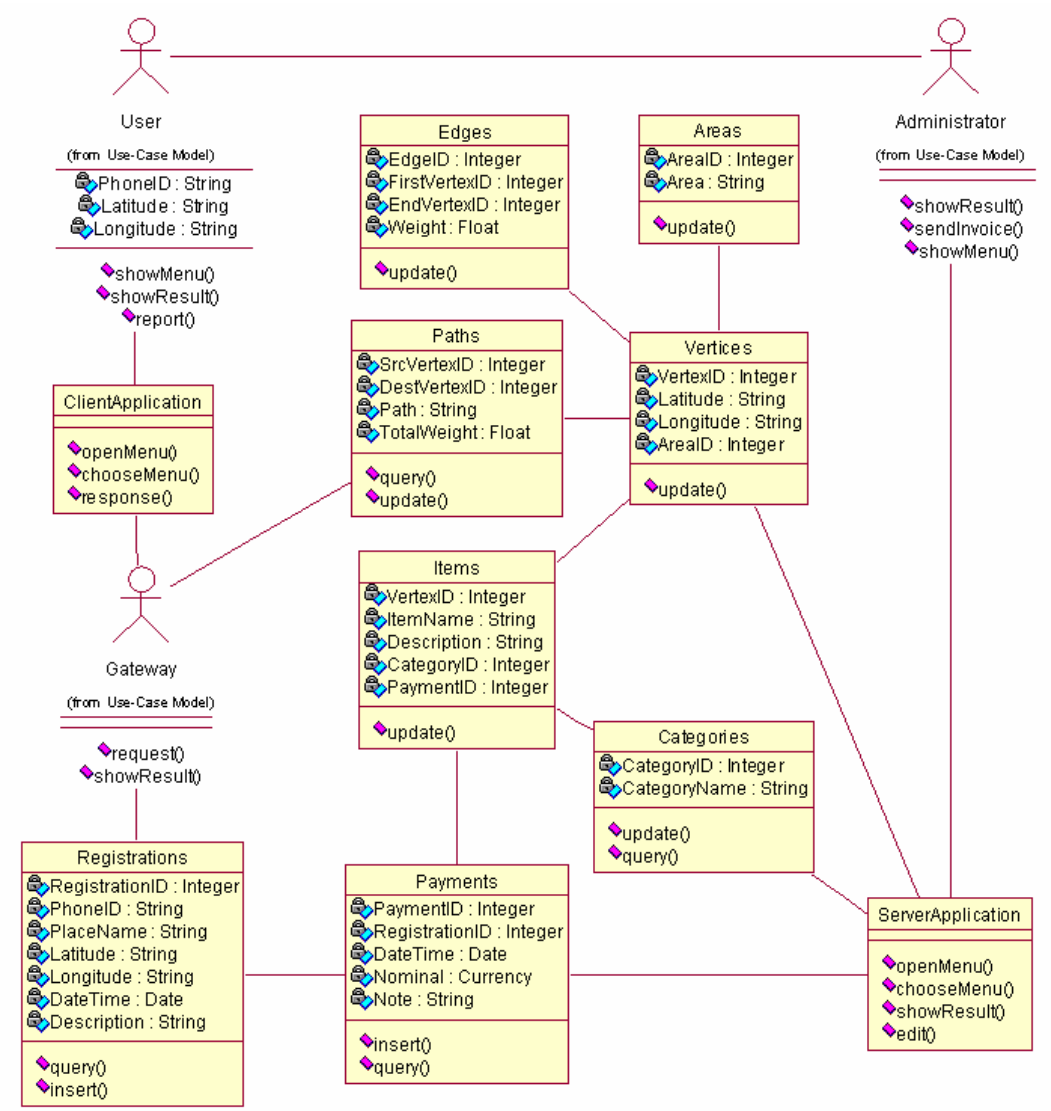

Gambar 8 Class Diagram 


\section{Implementasi Piranti Lunak}

Piranti keras dan piranti lunak dibutuhkan agar sistem yang dibuat dapat berjalan dengan baik. Piranti lunak dirancang untuk administrator dan pengguna (user). Administrator dapat menentukan arah jalan, apakah satu arah (one way) atau dua arah (two ways), menambah titik (tempat), atau menggeser titik. Administrator juga dapat melakukan pencarian rute terpendek dari satu titik ke titik lainnya, dan melakukan uji coba terhadap pencarian dari suatu titik ke titik tujuan. User dapat melihat status GPS, menampilkan peta serta menampilkan hasil permintaan rute terpendek yang dicari.

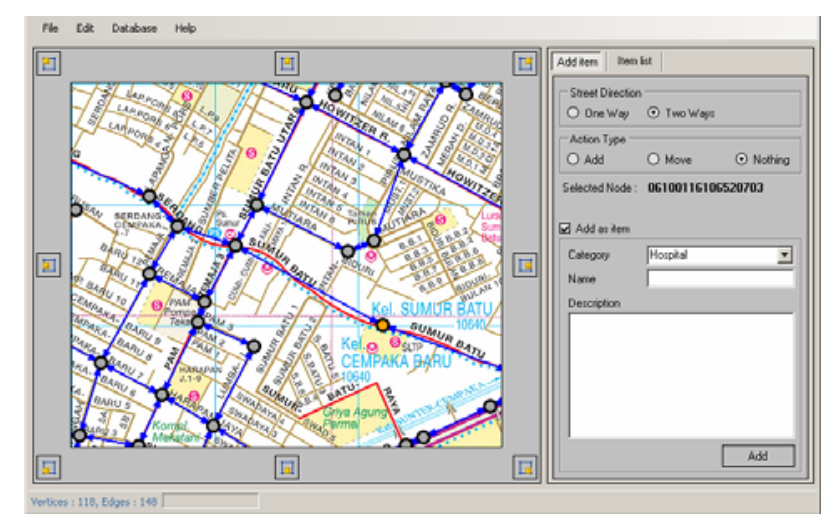

Gambar 9 Tampilan Layar untuk Menambah Status Tempat

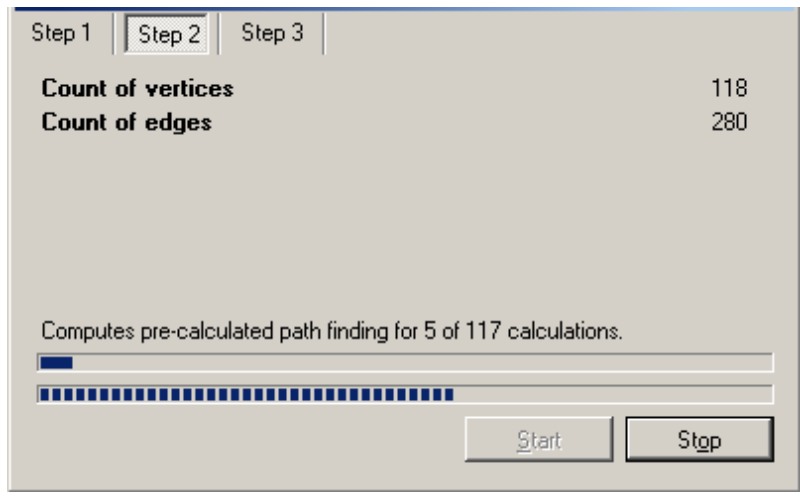

Gambar 10 Tampilan Layar untuk Proses Pencarian Rute Terpendek

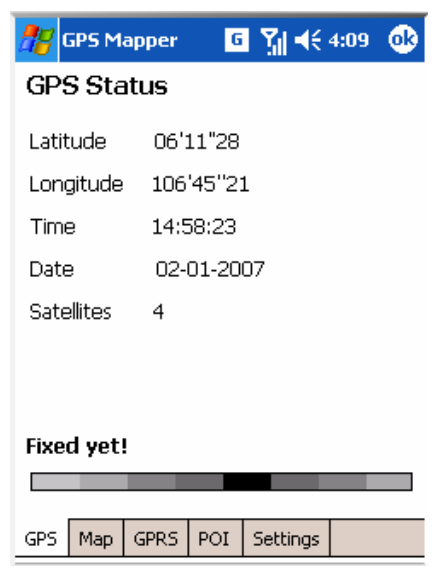

Gambar 11 Tampilan Layar Pertama atau Tab GPS 


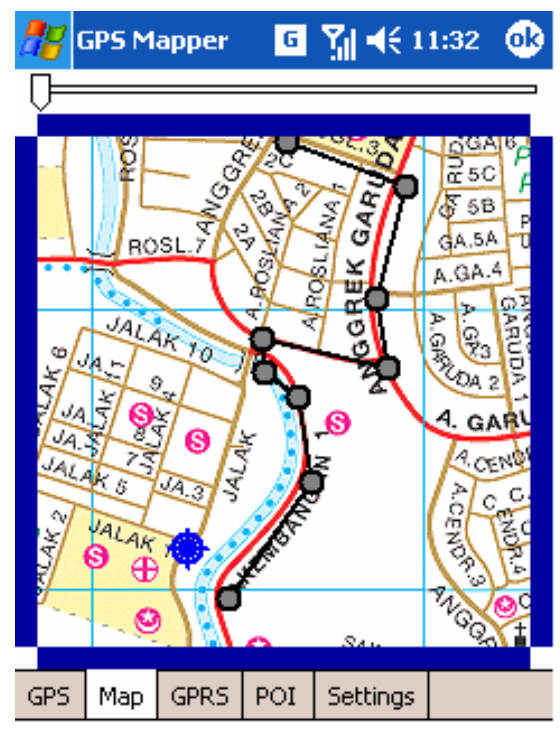

Gambar 12 Tampilan Layar Hasil Pencarian Rute Terpendek

\section{Evaluasi}

Evaluasi dilakukan untuk mengetahui lama waktu rata-rata yang dibutuhkan untuk mendapatkan rute terpendek pada aplikasi server dari 100, 200, 350 dan 500 titik. Evaluasi kestabilan program ini dilakukan dengan menggunakan 3 jenis prosesor, yaitu Intel Centrion $1.73 \mathrm{GHz}$, Intel Celeron 2.53 GHz, dan Intel Pentium 4 3.0 GHz.

Tabel 4 Spesifikasi Sistem pada Server yang Digunakan untuk Evaluasi

\begin{tabular}{|c|c|}
\hline Hardware & Softw are \\
\hline Memori 1 GB & Windows XP SP2 \\
Hard Disk 60 GB 5400 rpm & .NET Framework 2.0 \\
QWERTY Keyboard & Microsoft SQL Server 2000 SP4 \\
Mouse & \\
Monitor resolusi 1024 x 768 & \\
\hline
\end{tabular}

Tabel 5 Hasil Pengujian untuk 100 Verteks

\begin{tabular}{|c|r|r|r|r|r|r|}
\hline \multirow{2}{*}{ Pengujian ke- } & \multicolumn{2}{|c|}{ Centrino 1.73 GHz } & \multicolumn{2}{c|}{ Celeron 2.53 GHz } & \multicolumn{2}{c|}{ Pentium 4 3.0 GHz } \\
\cline { 2 - 6 } & $\begin{array}{c}\text { Waktu } \\
\text { (menit:detik) }\end{array}$ & $\begin{array}{c}\text { Waktu } \\
\text { (milidetik) }\end{array}$ & $\begin{array}{c}\text { Waktu } \\
\text { (menit:detik) }\end{array}$ & $\begin{array}{c}\text { Waktu } \\
\text { (milidetik) }\end{array}$ & $\begin{array}{c}\text { Waktu } \\
\text { (menit:detik) }\end{array}$ & $\begin{array}{c}\text { Waktu } \\
\text { (milidetik) }\end{array}$ \\
\hline 1 & $0: 9.136$ & 9136 & $0: 6.247$ & 6247 & $0: 5.257$ & 5257 \\
2 & $0: 10.031$ & 10031 & $0: 6.858$ & 6858 & $0: 5.782$ & 5782 \\
3 & $0: 9.237$ & 9237 & $0: 6.322$ & 6322 & $0: 5.328$ & 5328 \\
4 & $0: 9.338$ & 9338 & $0: 6.386$ & 6386 & $0: 5.372$ & 5372 \\
5 & $0: 9.209$ & 9209 & $0: 6.297$ & 6297 & $0: 5.305$ & 5305 \\
6 & $0: 9.99$ & 9990 & $0: 6.833$ & 6833 & $0: 5.757$ & 5757 \\
7 & $0: 9.327$ & 9327 & $0: 6.373$ & 6373 & $0: 5.371$ & 5371 \\
8 & $0: 10.128$ & 10128 & $0: 6.919$ & 6919 & $0: 5.832$ & 5832 \\
9 & $0: 9.102$ & 9102 & $0: 6.221$ & 6221 & $0: 5.238$ & 5238 \\
10 & $0: 10.308$ & 10308 & $0: 7.046$ & 7046 & $0: 5.938$ & 5938 \\
\hline Total Waktu & $\mathbf{1 : 3 5 . 8 0 6}$ & $\mathbf{9 5 8 0 6}$ & $\mathbf{1 : 5 . 5 0 1}$ & $\mathbf{6 5 5 0 1}$ & $\mathbf{0 : 5 5 . 1 7 8}$ & $\mathbf{5 5 1 7 8}$ \\
\hline Rata-rata & $\mathbf{0 : 9 . 5 8 0 6}$ & $\mathbf{9 5 8 0 . 6}$ & $\mathbf{0 : 6 . 5 5}$ & $\mathbf{6 5 5 0}$ & $\mathbf{0 : 5 . 5 1 8}$ & $\mathbf{5 5 1 8}$ \\
\hline
\end{tabular}


Tabel 6 Hasil Pengujian untuk 200 Verteks

\begin{tabular}{|c|c|c|c|c|c|c|}
\hline \multirow[b]{2}{*}{ Pengujian ke- } & \multicolumn{2}{|c|}{ Centrino $1.73 \mathrm{GHz}$} & \multicolumn{2}{|c|}{ Celeron $2.53 \mathrm{GHz}$} & \multicolumn{2}{|c|}{ Pentium 43.0 GHz } \\
\hline & $\begin{array}{c}\text { Waktu } \\
\text { (menit:detik) }\end{array}$ & $\begin{array}{c}\text { Waktu } \\
\text { (milidetik) }\end{array}$ & $\begin{array}{c}\text { Waktu } \\
\text { (menit:detik) }\end{array}$ & $\begin{array}{c}\text { Waktu } \\
\text { (milidetik) }\end{array}$ & $\begin{array}{c}\text { Waktu } \\
\text { (menit:detik) }\end{array}$ & $\begin{array}{c}\text { Waktu } \\
\text { (milidetik) }\end{array}$ \\
\hline 1 & $0: 43.424$ & 43424 & $0: 29.692$ & 29692 & $0: 25.01$ & 25010 \\
\hline 2 & $0: 44.68$ & 44680 & $0: 30.543$ & 30543 & $0: 25.744$ & 25744 \\
\hline 3 & $0: 41.362$ & 41362 & $0: 28.279$ & 28279 & $0: 23.825$ & 23825 \\
\hline 4 & $0: 41.419$ & 41419 & $0: 28.32$ & 28320 & $0: 23.854$ & 23854 \\
\hline 5 & $0: 43.639$ & 43639 & $0: 29.838$ & 29838 & $0: 25.135$ & 25135 \\
\hline 6 & $0: 42.243$ & 42243 & $0: 28.881$ & 28881 & $0: 24.328$ & 24328 \\
\hline 7 & $0: 42.458$ & 42458 & $0: 29.026$ & 29026 & $0: 24.46$ & 24460 \\
\hline 8 & $0: 42.374$ & 42374 & $0: 28.983$ & 28983 & $0: 24.414$ & 24414 \\
\hline 9 & $0: 43.385$ & 43385 & $0: 29.667$ & 29667 & $0: 24.996$ & 24996 \\
\hline 10 & $0: 42.366$ & 42366 & $0: 28.967$ & 28967 & $0: 24.401$ & 24401 \\
\hline Total Waktu & $7: 7.35$ & 427350 & 4:52.195 & 292195 & $4: 6.168$ & 246168 \\
\hline Rata-rata & $0: 42.735$ & 42735 & $0: 29.219$ & 29219 & $0: 24.617$ & 24617 \\
\hline
\end{tabular}

Tabel 7 Hasil Pengujian untuk 350 Verteks

\begin{tabular}{|c|r|r|r|r|r|r|}
\hline \multirow{2}{*}{ Pengujian ke-- } & \multicolumn{2}{|c|}{ Centrino 1.73 GHz } & \multicolumn{2}{c|}{ Celeron 2.53 GHz } & \multicolumn{2}{c|}{ Pentium 4 3.0 GHz } \\
\cline { 2 - 6 } & $\begin{array}{c}\text { Waktu } \\
\text { (menit:detik) }\end{array}$ & $\begin{array}{c}\text { Waktu } \\
\text { (milidetik) }\end{array}$ & $\begin{array}{c}\text { Waktu } \\
\text { (menit:detik) }\end{array}$ & $\begin{array}{c}\text { Waktu } \\
\text { (milidetik) }\end{array}$ & $\begin{array}{c}\text { Waktu } \\
\text { (menit:detik) }\end{array}$ & $\begin{array}{c}\text { Waktu } \\
\text { (milidetik) }\end{array}$ \\
\hline 1 & $2: 46.629$ & 166629 & $1: 53.947$ & 113947 & $1: 35.986$ & 95986 \\
2 & $2: 41.516$ & 161516 & $1: 50.44$ & 110440 & $1: 33.032$ & 93032 \\
3 & $2: 43.762$ & 163762 & $1: 51.974$ & 111974 & $1: 34.327$ & 94327 \\
4 & $2: 44.522$ & 164522 & $1: 52.496$ & 112496 & $1: 34.771$ & 94771 \\
5 & $2: 41.126$ & 161126 & $1: 50.176$ & 110176 & $1: 32.808$ & 92808 \\
6 & $2: 41.716$ & 161716 & $1: 50.587$ & 110587 & $1: 33.152$ & 93152 \\
7 & $2: 41.324$ & 161324 & $1: 50.317$ & 110317 & $1: 32.918$ & 92918 \\
8 & $2: 44.321$ & 164321 & $1: 52.365$ & 112365 & $1: 34.648$ & 94648 \\
9 & $2: 49.533$ & 169533 & $1: 55.929$ & 115929 & $1: 37.649$ & 97649 \\
10 & $2: 43.901$ & 163901 & $1: 52.077$ & 112077 & $1: 34.41$ & 94410 \\
\hline Total Waktu & $\mathbf{2 7 : 1 8 . 3 5}$ & $\mathbf{1 6 3 8 3 5 0}$ & $\mathbf{1 8 : 4 0 . 3 0 9}$ & $\mathbf{1 1 2 0 3 0 9}$ & $\mathbf{1 5 : 4 3 . 7 0 1}$ & $\mathbf{9 4 3 7 0 1}$ \\
\hline Rata-rata & $\mathbf{2 : 4 3 . 8 3 5}$ & $\mathbf{1 6 3 8 3 5}$ & $\mathbf{1 : 5 2 . 0 3 1}$ & $\mathbf{1 1 2 0 3 1}$ & $\mathbf{1 : 3 4 . 3 7}$ & $\mathbf{9 4 3 7 0}$ \\
\hline
\end{tabular}

Tabel 8 Hasil Pengujian untuk 500 Verteks

\begin{tabular}{|c|r|r|r|r|r|r|}
\hline \multirow{2}{*}{ Pengujian ke- } & \multicolumn{2}{|c|}{ Centrino 1.73 GHz } & \multicolumn{1}{c|}{ Celeron 2.53 GHz } & \multicolumn{2}{c|}{ Pentium 4 3.0 GHz } \\
\cline { 2 - 6 } & $\begin{array}{c}\text { Waktu } \\
\text { (menit:detik) }\end{array}$ & $\begin{array}{c}\text { Waktu } \\
\text { (milidetik) }\end{array}$ & $\begin{array}{c}\text { Waktu } \\
\text { (menit:detik) }\end{array}$ & $\begin{array}{c}\text { Waktu } \\
\text { (milidetik) }\end{array}$ & $\begin{array}{c}\text { Waktu } \\
\text { (menit:detik) }\end{array}$ & $\begin{array}{c}\text { Waktu } \\
\text { (milidetik) }\end{array}$ \\
\hline 1 & $9: 38.198$ & 578198 & $6: 35.372$ & 395372 & $5: 33.039$ & 333039 \\
2 & $6: 36.767$ & 396767 & $4: 31.312$ & 271312 & $3: 48.541$ & 228541 \\
3 & $6: 34.933$ & 394933 & $4: 30.049$ & 270049 & $3: 47.477$ & 227477 \\
4 & $6: 32.404$ & 392404 & $4: 28.326$ & 268326 & $3: 46.025$ & 226025 \\
5 & $6: 31.968$ & 391968 & $4: 28.034$ & 268034 & $3: 45.772$ & 225772 \\
6 & $6: 32.881$ & 392881 & $4: 28.651$ & 268651 & $3: 46.305$ & 226305 \\
7 & $6: 35.358$ & 395358 & $4: 30.35$ & 270350 & $3: 47.727$ & 227727 \\
8 & $6: 29.957$ & 389957 & $4: 26.652$ & 266652 & $3: 44.623$ & 224623 \\
9 & $6: 32.136$ & 392136 & $4: 28.15$ & 268150 & $3: 45.872$ & 225872 \\
10 & $6: 31.052$ & 391052 & $4: 27.406$ & 267406 & $3: 45.248$ & 225248 \\
\hline Total Waktu & $\mathbf{6 8 : 3 5 . 6 5 4}$ & $\mathbf{4 1 1 5 6 5 4}$ & $\mathbf{4 6 : 5 4 . 3 0 2}$ & $\mathbf{2 8 1 4 3 0 2}$ & $\mathbf{3 9 : 3 0 . 6 2 8}$ & $\mathbf{2 3 7 0 6 2 8}$ \\
\hline Rata-rata & $\mathbf{6 : 5 1 . 5 6 5 4}$ & $\mathbf{4 1 1 5 6 5 . 4}$ & $\mathbf{4 : 4 1 . 4 3}$ & $\mathbf{2 8 1 4 3 0}$ & $\mathbf{3 : 5 7 . 0 6 3}$ & $\mathbf{2 3 7 0 6 3}$ \\
\hline
\end{tabular}




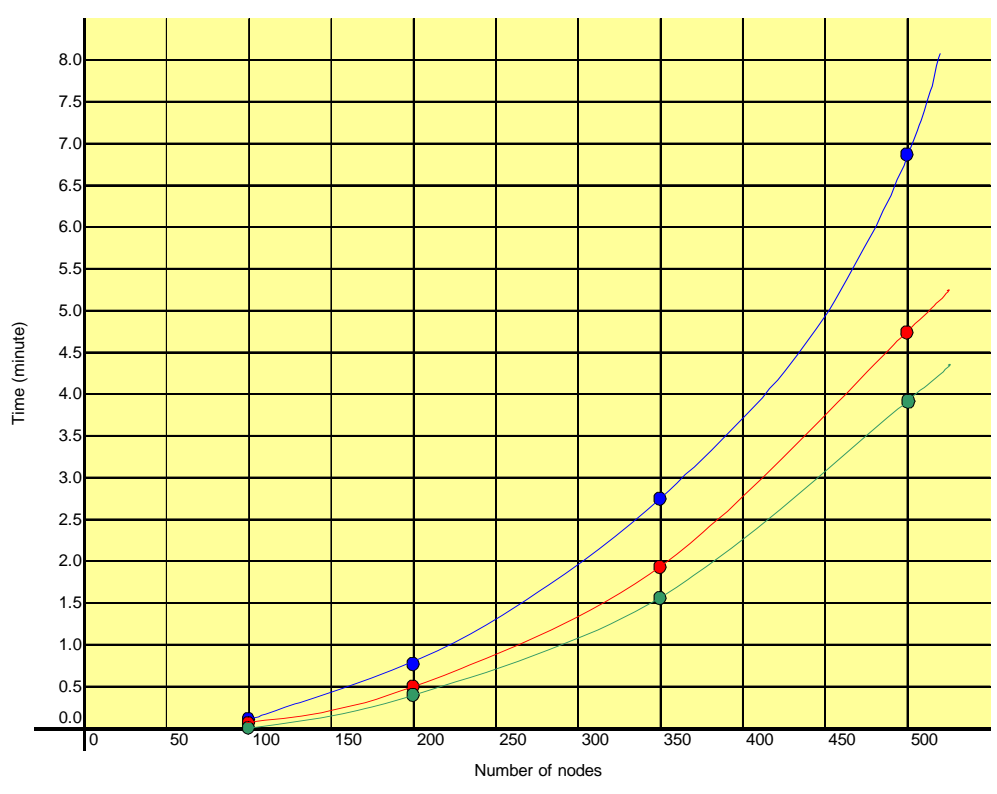

- Prosesor Intel Centrino $1.73 \mathrm{GHz}$

- Prosesor Intel Celeron $2.53 \mathrm{GHz}$

- Prosesor Intel Pentium $43.0 \mathrm{GHz}$

Gambar 13 Grafik Hasil Pengujian Pencarian Rute Terpendek

\section{SIMPULAN}

Simpulan yang diperoleh dari penelitian ini, yaitu algoritma Dijkstra metode Fibonacci Heap memiliki waktu yang lebih cepat dalam mencari rute terpendek dibandingkan dengan algoritma Dijktra metode biasa dan Bellman Ford; Dengan adanya aplikasi seperti ini, memungkinkan pengguna PDA yang dilengkapi GPS mendapatkan informasi rute terpendek; Aplikasi ini mampu menyajikan data GPS berupa lokasi tempat ke dalam bentuk grafikal (peta) yang lebih mudah untuk dipahami dibandingkan data-data dalam bentuk koordinat global; Kecepatan pemrosesan data pada saat nodes training sangat dipengaruhi oleh spesifikasi piranti keras yang digunakan. Untuk data yang lebih banyak peningkatan piranti keras yang lebih baik sangat dibutuhkan.

Saran untuk penelitian dan pengembangan lebih lanjut, yaitu peta wilayah diperluas; Informasi yang dihasilkan bukan hanya rute terpendek tapi bisa pula rute tercepat dengan memperhatikan faktor kemacetan; Penggunaan peta vector sebagai peta dasar akan meningkatkan kecepatan aplikasi dalam menampilkan peta, dan memperkecil media penyimpanan yang dibutuhkan; Meningkatkan keakuratan posisi yang dihasilkan dengan membangun sistem peta khusus (tipe vector) yang didapat dengan melakukan plotting atau pemetaan beberapa tempat dengan menggunakan alat GPS langsung; Aplikasi lebih dikembangkan lagi agar pengguna dapat membentuk suatu komunitas sendiri sehingga dapat mengetahui informasi posisi pengguna lain dalam komunitasnya; Aplikasi dilengkapi dengan fasilitas panduan penggunaan. 


\section{DAFTAR PUSTAKA}

Ambler, S. W. A manager's introduction to the Rational Unified Process (RUP). Retrieved 2007 from http://www.ambysoft.com/downloads/managersIntroToRUP.pdf

Anonymous1. Fibonacci heap. Retrieved 2007 from http://en.wikipedia.org/wiki/Fibonacci_heap

Anonymous2. Coordinate system. Retrieved 2007 from http://en.wikipedia.org/wiki/Coordinate system

Anonymous3. GPS. Retrieved 2007 from http://en.wikipedia.org/wiki/GPS

Anonymous4. GPRS. Retrieved 2007 from http://en.wikipedia.org/wiki/GPRS

Anonymous5. Location based service. Retrieved 2007 from http://en.wikipedia.org/wiki/Location_based_service

Anonymous6. NMEA. Retrieved 2007 from http://en.wikipedia.org/wiki/NMEA

Anonymous7. Rational unified process. Retrieved 2007 from http://www.therationaledge.com/content/jan 01/f rup_pk.html

Anonymous8. Rational unified process. Retrieved 2007 from http://en.wikipedia.org/wiki/Rational Unified Process

Booch, Gr., James R., and Ivar J. (1999). The unified modeling language user guide, United States of America: Addison Wesley.

Horowitz, E., Sahni. S, and Rajasekaran, S. (1998). Computer algorithms/C++, United States of America: Computer Science Press.

Johnsonbaugh, R. (2001). Discrete mathematics, $5^{\text {th }}$ ed., United States of America: Prentice Hall.

Magon, A., and R. Shukla. LBS, the ingredients and the alternatives. Retrieved 2007 from http://www.gisdevelopment.net/technology/lbs/techlbs006.htm 